\title{
Immunohistochemical analysis of possible chemoresistance markers identified by micro-arrays on serous ovarian carcinomas
}

\author{
Bernard Têtu ${ }^{1,2}$, Ion Popa ${ }^{1,2}$, Isabelle Bairati ${ }^{2}$, Sylvain L'Esperance ${ }^{2,3}$, \\ Magdalena Bachvarova ${ }^{2}$, Marie Plante ${ }^{2,4}$, François Harel ${ }^{2}$ and Dimcho Bachvarov ${ }^{2,3}$
}

${ }^{1}$ Department of Pathology, Centre Hospitalier Universitaire de Québec (CHUQ), L'Hotel-Dieu de Québec, Faculty of Medicine, Laval University Québec, Québec, Canada; ${ }^{2}$ Cancer Research Centre, Centre Hospitalier Universitaire de Québec (CHUQ), L’Hotel-Dieu de Québec, Faculty of Medicine, Laval University Québec, Québec, Canada; ${ }^{3}$ Department of Medicine, Centre Hospitalier Universitaire de Québec (CHUQ), L'Hotel-Dieu de Québec, Faculty of Medicine, Laval University Québec, Québec, Canada and ${ }^{4}$ Department of Gynecologic Oncology, Centre Hospitalier Universitaire de Québec (CHUQ), L'Hotel-Dieu de Québec, Faculty of Medicine, Laval University Québec, Québec, Canada

\begin{abstract}
Using the DNA microarray technology, we have identified genes that are differentially expressed in chemosensitive and chemoresistant ovarian serous papillary carcinomas and could potentially distinguish ovarian cancer patients based on their response to chemotherapy. The present study aims to evaluate the clinical usefulness of overexpression of selected genes by immunohistochemistry. Our cohort included 158 women who were operated on and received chemotherapy for an advanced serous papillary ovarian carcinoma (FIGO stages III and IV). The end point used in this study was progression-free survival. Immunohistochemistry was performed on microarray blocks containing all 158 cases. Twelve commercially available antibodies were selected. Of them, 10 corresponded to differentially expressed genes in our micro-array study and p53 and Ki67 were included. Antibodies were obtained for the following selected genes: GSTA1, MMP1, FOSB, CTSL2, HSP10, CD36, CXCL2, RBBP7, Siva, and PTGDS. Cox proportional hazards models, adjusted for standard risk factors, were used to estimate the associations between the markers and progression-free survival. No association was found between mRNA level and protein expression by immunohistochemistry. In multivariate analyses, patients whose tumors overexpressed HSP10 had a lower risk of progression than those with low expression (HR: 0.6 ; $\mathrm{Cl}: 0.42-0.87 ; \boldsymbol{P}=0.007$ ). High level of proliferation (Ki67) tended to be associated with a lower risk of progression (HR: $0.72 ; \mathrm{Cl}$ : $0.51-1.03 ; P=0.07$ ) whereas MMP1 overexpression tended to be associated with a higher risk of progression (HR: $1.61 ; \mathrm{Cl}$ : $0.94-2.79 ; P=0.08$ ). Our study shows that gene expression analysis coupled with immunohistochemistry allowed the identification of HSP10 as an independent factor of progression-free survival.

Modern Pathology (2008) 21, 1002-1010; doi:10.1038/modpathol.2008.80; published online 23 May 2008
\end{abstract}

Keywords: serous ovarian carcinoma; chemoresistance; HSP10; DNA microarray; immunohistochemistry

Ovarian cancer is responsible for more cancer deaths among women in the Western world than any other gynecologic malignancy. ${ }^{1}$ An initial surgical approach is essential for aggressive cytoreduction and proper staging of the disease, since minimal residual tumor after surgery is a major

Correspondence: Dr B Têtu, MD, Department of Pathology, Centre Hospitalier Universitaire de Québec (CHUQ), L’Hôtel-Dieu de Québec, 11, Côte du Palais, Québec City, Québec G1R 2J6, Canada. E-mail: bernard.tetu@chuq.qc.ca

Received 14 January 2008; revised 21 March 2008; accepted 24 March 2008; published online 23 May 2008 factor of better response to chemotherapy and survival. $^{2}$ Intravenous combinated chemotherapy with taxol plus carboplatin is the current regimen of choice for the treatment of advanced ovarian cancer and is followed by a $50 \%$ complete pathologic remission rate. ${ }^{3}$

Resistance to chemotherapy is, however, a major concern. Indeed, although significant proportions of women respond to chemotherapy, the majority of responders (approximately 60-75\%) eventually relapses and dies from recurrent disease while $20-30 \%$ of patients never experience a clinical remission. ${ }^{4}$ Chemotherapy resistance in ovarian 
cancer is broad and encompasses diverse, unrelated drugs, suggesting more than one mechanism of resistance. Until now, very few markers were found to predict tumor response to chemotherapy and prognosis in ovarian cancer. ${ }^{5-7}$ Recent advances in microarray technology led to identification of gene signatures that can help to improve diagnosis of ovarian cancer ${ }^{8}$ and in vitro drug resistance ${ }^{9,10}$ but not clinical response to chemotherapy. ${ }^{11}$

We recently analyzed the gene expression patterns in advanced (FIGO stages III and IV) primary serous papillary carcinomas of the ovary displaying different response to first line chemotherapy in an attempt to identify specific molecular signatures associated with clinical response to chemotherapy. ${ }^{12,13}$ Initially, the expression profiles of 15 chemoresistant serous papillary carcinomas (recurrence $\leq 6$ months) and 10 chemosensitive serous papillary carcinomas (recurrence $\geq 30$ months) tumors were independently analyzed which allowed the identification of 155 genes with different expression in the chemoresistant or the chemosensitive phenotype. The 155 genes differently expressed at a $P$-value cutoff of 0.01 were upregulated or downregulated at least 2-fold in chemoresistant tumors in comparison with chemosensitive tumors. Functional classes of these differently expressed genes mainly include metabolism (30\%), cell growth and maintenance (18\%), signal transduction (12\%), immune response (12\%), cell organization and biogenesis $(11 \%)$, transport $(9 \%)$ and apoptosis $(3 \%)$; the remainder $(5 \%)$ have unknown functions.

This experiment prompted us to test the hypothesis that the detection of corresponding markers at the protein level by immunohistochemistry may prove clinically applicable to the daily practice of pathology to predict the response to chemotherapy. We decided to analyze 10 markers for which commercial antibodies were available on an independent, uniform cohort of patients with serous papillary carcinomas.

\section{Materials and methods}

Patients included in this study were operated between January 1998 to December 2003 for an advanced ovarian cancer at the CHUQ-L'Hôtel-Dieu hospital in Quebec City, Canada. Inclusion criteria were: serous papillary carcinoma histology, FIGO Stages III or IV and chemotherapy received after the surgery. The grade was evaluated using criteria defined by Silverberg, ${ }^{14}$ which was in use in our institution during the accrual period. Clinical response to chemotherapy was evaluated using modified RECIST criteria. ${ }^{15}$ The follow-up was available until death or to the date the study was closed (31 July 2004). The study was approved by the Institutional Ethical Committee.
One representative block of each ovarian tumor was selected for the preparation of the tissue arrays. Three $0.6 \mathrm{~mm}$ cores of tumor were taken from each tumor block and placed, $0.4 \mathrm{~mm}$ apart, on a recipient paraffin block using a commercial tissue arrayer (Beecher Instruments, Sun Prairie, WI, USA). The cores were randomly placed on one of three recipient blocks to avoid immunohistochemistry evaluation biases. Four micron-thick sections were cut for the hematoxylin-eosin (H\&E) staining and immunohistochemistry analyses.

The antibodies were selected based on the capacity of the corresponding gene to predict ovarian cancer prognosis in our previous microarray study. ${ }^{13}$ A serious constraint was their commercial availability. The antibodies are presented in the Table 1. P53 and Ki-67 were included in our study because of their general interest in oncology. Immunohistochemistry staining was performed using the avidin-biotin complex method. Briefly, one representative $4 \mu \mathrm{m}$ tissue section was cut from the tissue array blocks. Sections were deparaffinized and rehydrated in graded alcohols, then incubated with blocking serum for $20 \mathrm{~min}$. The antibody dilutions, retrieval method, and incubation conditions are detailed in Table 2. Sections were incubated with a biotinylated secondary antibody (Dako, Carpinteria, CA, USA) and then exposed to a streptavidin complex (Dako, Carpinteria, CA, USA). Complete reaction was revealed by 3-3' diaminobenzidine and the slide was counterstained with hematoxylin. Positive controls used in each case are described in Table 2. Negative controls consisted of tissue sections incubated with phosphate-buffered saline $(0.16 \mathrm{M}, \mathrm{pH} \sim 7.5)$ instead of the primary antibody. For three antibodies (CD36, FOSB and MMP1) the staining was weak and we used the catalyzed signal amplification system (Dako, Carpinteria, CA, USA).

Positive staining was defined when more than $10 \%$ of cells expressed the marker, except for Ki-67 for which $20 \%$ was defined as a threshold. ${ }^{16}$ The relationship between marker expression and patients' age, tumor grade, tumor size and the type of chemotherapy received was evaluated by the $\chi^{2} t$-test. Cox regression analyses were performed to estimate the association between tumor expression and progression free survival. Progression free survival was defined as the time from surgery to the first observation of disease progression, recurrence or death. Multivariate analyses, taking into account standard or strongly associated prognostic variables, were performed to identify independent prognostic factors. A significant association was considered when $P$-value was below 0.05 and a trend for values between 0.05 and 0.1. KaplanMeier curves were done to show progression-free survival for each marker. The immunohistochemistry staining was analyzed independently by two pathologists (BT, IP) blinded to clinical data and progression. 
Table 1 Antibodies used in the study

\begin{tabular}{|c|c|c|c|c|}
\hline No. & Gene name/genbank & Antibody & Clone & Description \\
\hline 1 & PTGDS/AK075333 & $\begin{array}{l}\text { Prostaglandin D } \\
\text { synthase }\end{array}$ & Cayman ${ }^{\mathrm{a}} 10004344$ & $\begin{array}{l}\text { Mouse polyclonal antibody against prostaglandin } \mathrm{D} \\
\text { synthase (lipocalin-type, } \beta \text { trace) protein }\end{array}$ \\
\hline 2 & CD36/M98398 & CD36 & $\mathrm{SCBT}^{\mathrm{b}}$ sc-21772 & $\begin{array}{l}\text { Mouse monoclonal antibody against human leukocytes } \\
\text { CD36 antigen }\end{array}$ \\
\hline 3 & CXCL2/BC015753 & MIP2 & SCBT sc-1388 & $\begin{array}{l}\text { Goat polyclonal antibody against an epitope mapping at the } \\
\text { C terminus of MIP-2 }\end{array}$ \\
\hline 4 & FOSB/NM_006732 & FOSB & SCBT sc-8013 & $\begin{array}{l}\text { Mouse monoclonal antibody against amino acids } 75-150 \\
\text { mapping at the } \mathrm{N} \text { terminus of Fos B of human origin }\end{array}$ \\
\hline 5 & HSPE1/BC023518 & HSP10 & SCBT sc-20958 & $\begin{array}{l}\text { Rabbit polyclonal antibody against an epitope } \\
\text { corresponding to amino acids } 1-102 \text { representing full } \\
\text { length HSP10 of human origin }\end{array}$ \\
\hline 6 & CTSL2/AB001928 & Pan-cathepsin & SCBT sc-25537 & $\begin{array}{l}\text { Rabbit polyclonal antibody against an epitope } \\
\text { corresponding to amino acids } 34-333 \text { mapping at the C } \\
\text { terminus of cathepsin L of human origin }\end{array}$ \\
\hline 7 & MMP1/NM_002421 & MMP1 & SCBT sc-21731 & $\begin{array}{l}\text { Mouse monoclonal antibody against amino acids } 366-376 \\
\text { of MMP-1 of human origin }\end{array}$ \\
\hline 8 & GSTA1/S49975 & GST & Abcam $^{\mathrm{c}}$, ab856-6 & $\begin{array}{l}\text { Mouse monoclonal antibody against GST3 dimeric protein } \\
\text { consisting of two identical } 27 \mathrm{kDa} \text { subunits }\end{array}$ \\
\hline 9 & Siva/U82938 & Siva & SCBT sc-7436 & $\begin{array}{l}\text { Goat polyclonal antibody against an epitope mapping near } \\
\text { the } \mathrm{N} \text { terminus of Siva of human origin }\end{array}$ \\
\hline 10 & RBBP7/NM_002893 & RbAp46 & Abcam, ab3535 & $\begin{array}{l}\text { Mouse monoclonal antibody against retinoblastoma- } \\
\text { associated protein } 46 \text { (RbAp 46) }\end{array}$ \\
\hline 11 & & Ki67 & Dako $^{\mathrm{d}}$, MIB1 & $\begin{array}{l}\text { Mouse monoclonal antibody against the Ki- } 67 \text { antigen and } \\
\text { recombinant fragments of the Ki- } 67 \text { molecule }\end{array}$ \\
\hline 12 & & p53 & Dako, PAb240 & $\begin{array}{l}\text { Mouse monoclonal antibody against an epitope of the p53 } \\
\text { protein only exposed on mutant forms in which structural } \\
\text { mutations have altered the protein conformation }\end{array}$ \\
\hline
\end{tabular}

${ }^{\mathrm{a} C a y m a n}$ Chemicals, Ann Arbor, MI, USA.

${ }^{\mathrm{b}}$ Santa Cruz Biotechnology Inc., Santa Cruz, CA, USA.

${ }^{\mathrm{c}}$ Abcam Inc., Cambridge, MA, USA.

${ }^{\mathrm{d}}$ DakoCytomation Inc., Carpinteria, CA, USA.

\section{Results}

\section{The Study Population}

During the accrual period, we retrieved 235 consecutive cases operated in our hospital for an advanced serous papillary ovarian carcinoma, stage III and IV. Seventy-seven cases were excluded. Of them six refused chemotherapy, 10 died before the beginning of chemotherapy, clinical information were incomplete in 34 cases, in one case the stage was uncertain, eight patients had preoperative chemotherapy, one had a tumor of uncertain origin and 17 were still under chemotherapy at the last follow-up. A total of 158 cases responded to all inclusion criteria.

Table 3 shows the major clinical characteristics of the patients. The age ranged from 28 to 88 years (median: 61 years). Tumors were mainly grade 3 $(67 \%)$ and stage III $(78 \%)$. Seventeen patients had a second cancer, of them 10 were from the breast, three from the colon, one from the endometrium, two from the skin and there was one malignant lymphoma. A majority of patients $(71 \%)$ received an intravenous combination of platinum and taxol, which was associated with a lower risk of progression compared to other combinations (Hazard ratio: 0.44 [0.26;0.74]; $P=0.002$ ). The median baseline
CA125 was $800 \mathrm{U} / \mathrm{ml}$ and a higher than average CA125 level was associated with increased risk of progression (Hazard ratio: 1.72 [0.99; 2.97]; $P=0.05)$.

Figure 1 shows the status of the patients at the end of the chemotherapy regimen and their evolution during the study. Ninety-seven patients had a complete response, of whom 77 underwent recurrences and 32 finally died of their disease. Twentynine patients had partial response or stable disease at the end of the chemotherapy, of whom 21 had progression and 12 died. Thirty-two patients had progression of their cancer under chemotherapy and 21 died. The median follow-up period of the cohort was 26.1 months. Fifty percent of the patients had a progression or a recurrence within the first 12 months of follow-up. At 5 years, only $13 \%$ of patients are recurrence-free and $43 \%$ are alive.

Figure 2 shows examples of immunostaining with the different antibodies used in this study. MMP1 gave a cytoplasmic granular staining in cancer cells while stromal cells were negative (Figure 2a); CD36 was expressed in the cytoplasm of cancer cells and stromal cells were negative (Figure 2b); HSP10 showed a cytoplasmic and granular staining of both cancer and stromal cells (Figure 2c); FOSB showed a granular cytoplasmic staining mostly limited to 
Table 2 Dilution and technique used for each antibody

\begin{tabular}{|c|c|c|c|c|c|c|}
\hline No. & Antibody & Dilution & Retrieval & Incubation & Amplification & Positive control \\
\hline 1 & $\begin{array}{l}\text { Prostaglandin D } \\
\text { synthase }\end{array}$ & $1: 500$ & Pronase & $\begin{array}{l}2 \mathrm{~h} / \text { room } \\
\text { temperature }\end{array}$ & N/A & $\begin{array}{l}\text { Non small cell lung } \\
\text { carcinoma }\end{array}$ \\
\hline 2 & CD36 & $1: 100$ & Microwave & $\begin{array}{l}1 \mathrm{~h} / \text { room } \\
\text { temperature }\end{array}$ & $\mathrm{CSA}^{\mathrm{a}}$ & $\begin{array}{l}\text { Prostate carcinoma and } \\
\text { normal testis }\end{array}$ \\
\hline 3 & MIP2 & $1: 100$ & Microwave & $\begin{array}{l}1 \mathrm{~h} / \text { room } \\
\text { temperature }\end{array}$ & N/A & $\begin{array}{l}\text { Pancreatic } \\
\text { adenocarcinoma and } \\
\text { normal liver }\end{array}$ \\
\hline 4 & FOSB & $1: 500$ & Microwave & $\begin{array}{l}1 \mathrm{~h} / \text { room } \\
\text { temperature }\end{array}$ & CSA & $\begin{array}{l}\text { Breast invasive ductal } \\
\text { carcinoma }\end{array}$ \\
\hline 5 & HSP10 & $1: 100$ & Microwave & $4^{\circ} \mathrm{C}$ overnight & N/A & $\begin{array}{l}\text { Colon and uterine cervix } \\
\text { carcinomas }\end{array}$ \\
\hline 6 & Pan-cathepsin & $1: 100$ & Microwave & $\begin{array}{l}1 \mathrm{~h} / \text { room } \\
\text { temperature }\end{array}$ & N/A & $\begin{array}{l}\text { Breast invasive ductal } \\
\text { carcinoma and colon } \\
\text { adenocarcinoma }\end{array}$ \\
\hline 7 & MMP1 & $1: 250$ & Microwave & $\begin{array}{l}1 \mathrm{~h} / \text { room } \\
\text { temperature }\end{array}$ & CSA & $\begin{array}{l}\text { Breast invasive ductal } \\
\text { carcinoma and colon } \\
\text { adenocarcinoma }\end{array}$ \\
\hline 8 & GST & $1: 1$ & Microwave & $\begin{array}{l}1 \mathrm{~h} / \text { room } \\
\text { temperature }\end{array}$ & N/A & Colon adenocarcinoma \\
\hline 9 & Siva & $1: 10$ & Pronase & $\begin{array}{l}1 \mathrm{~h} / \text { room } \\
\text { temperature }\end{array}$ & N/A & Colon adenocarcinoma \\
\hline 10 & RbAp46 & $1: 500$ & No & $\begin{array}{l}1 \mathrm{~h} / \text { room } \\
\text { temperature }\end{array}$ & N/A & $\begin{array}{l}\text { Breast invasive ductal } \\
\text { carcinoma }\end{array}$ \\
\hline 11 & Ki67 & $1: 75$ & Microwave & $\begin{array}{l}1 \mathrm{~h} / \text { room } \\
\text { temperature }\end{array}$ & N/A & $\begin{array}{l}\text { Ovarian serous papillary } \\
\text { carcinoma }\end{array}$ \\
\hline 12 & p53 & $1: 500$ & Microwave & $\begin{array}{l}1 \mathrm{~h} / \text { room } \\
\text { temperature }\end{array}$ & N/A & $\begin{array}{l}\text { Ovarian serous papillary } \\
\text { carcinoma }\end{array}$ \\
\hline
\end{tabular}

${ }^{\mathrm{a} C a t a l y z e d ~ s i g n a l ~ a m p l i f i c a t i o n ~ s y s t e m ~(D a k o) . ~}$

cancer cells (Figure 2d); GST had a diffuse cytoplasmic staining limited to cancer cells (Figure 2e); pan-cathepsin was present in both cancer and stromal cells (Figure 2f); prostaglandin D synthetase was present in less than $5 \%$ of cancer cells and was not retained for this study; RbAp46 gave a strong positive nuclear staining in basically all cases and was not further analyzed; Siva and MIP2 were completely negative despite repeated attempts with various retrieval systems, antibody concentration, incubating time, or signal enhancements systems and were not retained for the study; p53 (Figure 2g) and Ki-67 (Figure 2h) gave a nuclear staining.

\section{Relation Between Markers and Risk Factors}

No association was found between CD36, HSP10 and FOSB and any risk factor. MMP1 overexpression was associated with an older age $(P=0.01)$. Overexpression of GST was positively associated with higher initial serum CA15 $(P=0.02)$. Pancathepsin expression was associated with higher grade $(P=0.02)$ and higher initial CA125 levels $(P=0.01)$. p53 tended to be associated with an older age $(P=0.06)$. High Ki-67 levels $(>20 \%)$ was associated with higher grade $(0=0.03)$. Furthermore, we found no linear correlation between gene expression obtained by microarray and protein expression obtained by immunohistochemistry (data not shown).

\section{Relation Between Marker Expression and Progression- Free Survival}

Table 4 shows the prevalence of expression of each marker along with bivariate and multivariate analyses to predict progression-free survival. Multivariate analyses taking into account standard or strongly associated prognostic variables (age, grade, stage, type of chemotherapy, initial CA125) were performed to identify independent prognostic factors. Multivariate analyses showed a significant association between HSP10 expression and a lower risk of progression after chemotherapy (HR: 0.6; CI: $0.42-0.87 ; P=0.007)$. A Kaplan-Meier curve for HSP10 and progression-free survival is depicted in the Figure 3. High proliferation rate (Ki67>20\%) showed a tendency to predict a lower risk of progression post chemotherapy (HR: 0.72; CI: $0.51-1.03 ; P=0.07)$. A trend was found for MMP1 overexpression to predict a higher risk of progression (HR: 1.61; CI: $0.94-2.79 ; P=0.08$ ).

\section{Discussion}

Our study shows that HSP10 is the only significant factor of delayed progression in patients exposed to chemotherapy. These findings confirm those of our micro-array study ${ }^{12}$ and are also consistent with the biology of HSP10.

Indeed, heat-shock proteins (HSPs) are important molecules in oncology. Five types of primary HSPs 
are currently known, and they are designated according to their molecular weight (HSP27, 60, 70, 90 and 110). ${ }^{17}$ HSPs bind and stabilize proteins to prevent the creation of aggregates during protein synthesis, transmembrane transport or stress, such as high temperatures. ${ }^{18}$ There are some cochaperones of low molecular weight that often form a

Table 3 Patients' characteristics

\begin{tabular}{|c|c|c|}
\hline Variable & $\mathrm{n} /$ total & $\%$ \\
\hline \multicolumn{3}{|l|}{ Age (years) } \\
\hline$<50$ & $27 / 158$ & 17.1 \\
\hline $50-69$ & 89/158 & 56.3 \\
\hline$>70$ & $42 / 158$ & 26.6 \\
\hline \multicolumn{3}{|l|}{ Median age } \\
\hline \multicolumn{3}{|l|}{61} \\
\hline \multicolumn{3}{|l|}{ Grade } \\
\hline 1 & $8 / 158$ & 5.1 \\
\hline 2 & $45 / 158$ & 28.4 \\
\hline 3 & $105 / 158$ & 66.5 \\
\hline \multicolumn{3}{|l|}{ Stage } \\
\hline III (A, B and C) & $123 / 158$ & 77.8 \\
\hline IV & $35 / 158$ & 22.2 \\
\hline \multicolumn{3}{|l|}{ Second cancer } \\
\hline Breast & $10 / 158$ & 6.3 \\
\hline Colon & $3 / 158$ & 1.9 \\
\hline Endometrium & $1 / 158$ & 0.6 \\
\hline Skin & $2 / 158$ & 1.3 \\
\hline Lymphoma & $1 / 158$ & 0.6 \\
\hline \multicolumn{3}{|c|}{ Type of chemotherapy } \\
\hline Platinum+taxol & $112 / 158$ & 70.9 \\
\hline Other & $46 / 158$ & 29.1 \\
\hline \multicolumn{3}{|c|}{ CA125 initial $(\mathrm{U} / \mathrm{ml})$} \\
\hline$<800$ & $72 / 158$ & 45.6 \\
\hline$>800$ & $69 / 158$ & 43.6 \\
\hline N/D & $17 / 158$ & 10.8 \\
\hline
\end{tabular}

biologically active complex. The HSP10-HSP40 complex is known to facilitate interactions between primary HSP and the substrate. ${ }^{17}$ The HSP10-HSP60 complex is involved in apoptosis through caspase activation. ${ }^{19}$ Therefore, in cases with constitutively low HSP10 levels, chemoresistance, as we observed, may be explained by a lack of capacity to induce apoptosis. However, in another micro-array study, HSP10 mRNA was found to be overexpressed in breast cancer cell cultures exposed to oxyplatin and 5-FU, suggesting that HSP10 overexpression, rather than low expression, might be associated with chemoresistance. ${ }^{20}$ However, in such an instance, higher HSP10 levels might not be associated with chemoresistance but might rather be induced by exposure to chemotherapy agents. ${ }^{18,19}$

In addition to the reaction to stress, HSPs play an important role in carcinogenesis. HSP60 and its cochaperone HSP10 are expressed early during the development of a malignant phenotype. ${ }^{21}$ In colon and uterine cervix cancers, HSP 10 and 60 expression levels are increased as cells progress from their normal state to dysplasia and cancer. ${ }^{19,22}$ HSPs are not expressed only by cancer cells. Indeed, higher levels of HSPs 10 and 60 were found in the cytoplasm of lymphocytes in lymph nodes with metastatic colon cancer than in non-metastatic lymph nodes. ${ }^{23}$ The presence of HSP10 was also detected in the serum and ascites from ovarian cancer patients and it was found that HSP10 in the serum may play a role in $\mathrm{T}$ lymphocyte inhibition, allowing cancer cells to escape immunitary surveillance. ${ }^{24}$

However, the prognostic significance of HSPs is not clear. In head and neck cancer ${ }^{25}$ and in breast cancer, ${ }^{26}$ HSP27 was not found to predict survival but HSP27 predicted neck cancer failure after radiation therapy. ${ }^{27} \mathrm{~A}$ few studies investigated the role of HSPs in ovarian cancer. HSP27 was not found to predict response to chemotherapy ${ }^{5}$ but HSP

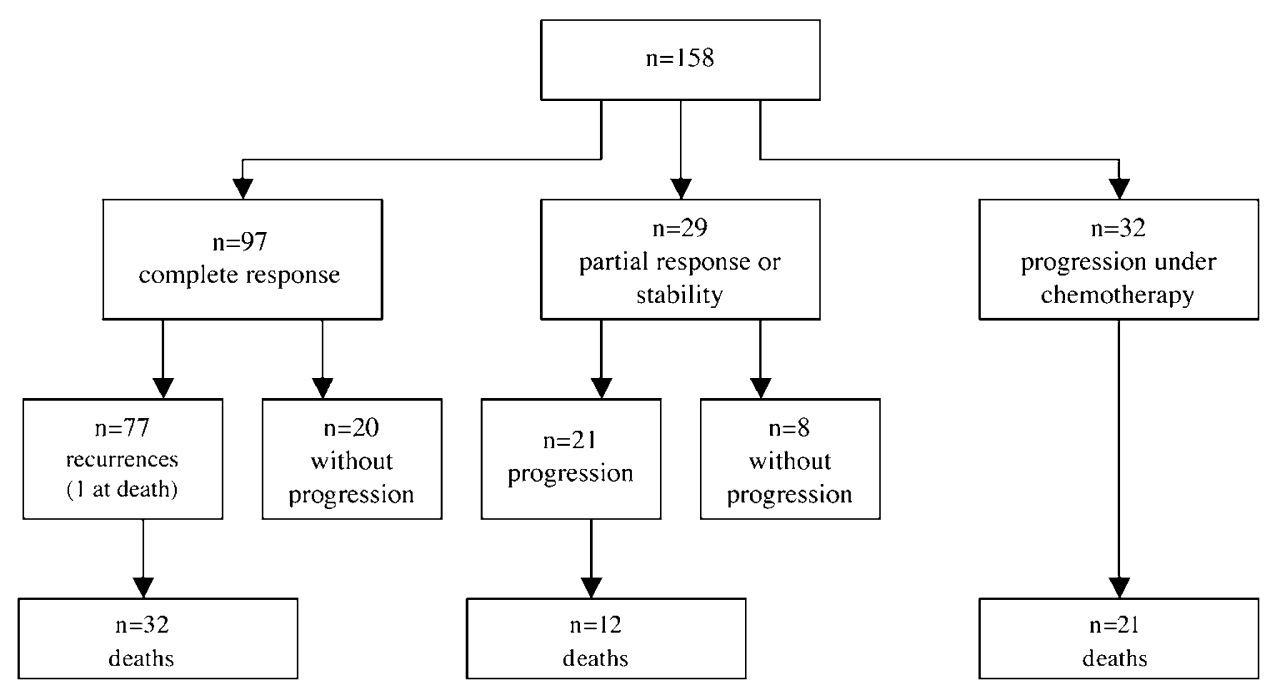

Figure 1 Distribution of patients according to their response to chemotherapy and evolution. 
60 overexpression was associated with a poor prognosis. ${ }^{28}$

In our study, Ki-67 failed to significantly predict progression-free survival. However, high proliferation rate was associated with higher tumor grade and Ki-67 tended to predict a better survival without progression, suggesting that high proliferation is associated with chemosensitivity. This is consistent with data from the literature, high proliferation rate, as measured by Ki-67, being a marker of recurrence in soft tissue sarcoma, ${ }^{29}$ head and neck cancer ${ }^{30}$ and urothelial tumors. ${ }^{31}$ It also predicted response to neoadjuvant anthracycline-based chemotherapy in breast cancer ${ }^{32}$ and response to radiation therapy in head and neck cancer. ${ }^{16,33}$

In advanced ovarian carcinoma, high Ki-67 index was predictive of recurrence ${ }^{34}$ and poor prognosis. ${ }^{35,36}$ However, as in our study, low proliferation predicted poor response to chemotherapy in ovarian carcinomas. ${ }^{37}$

In our study, there was a tendency for MMP1 to predict a poorer progression-free survival. MMP1
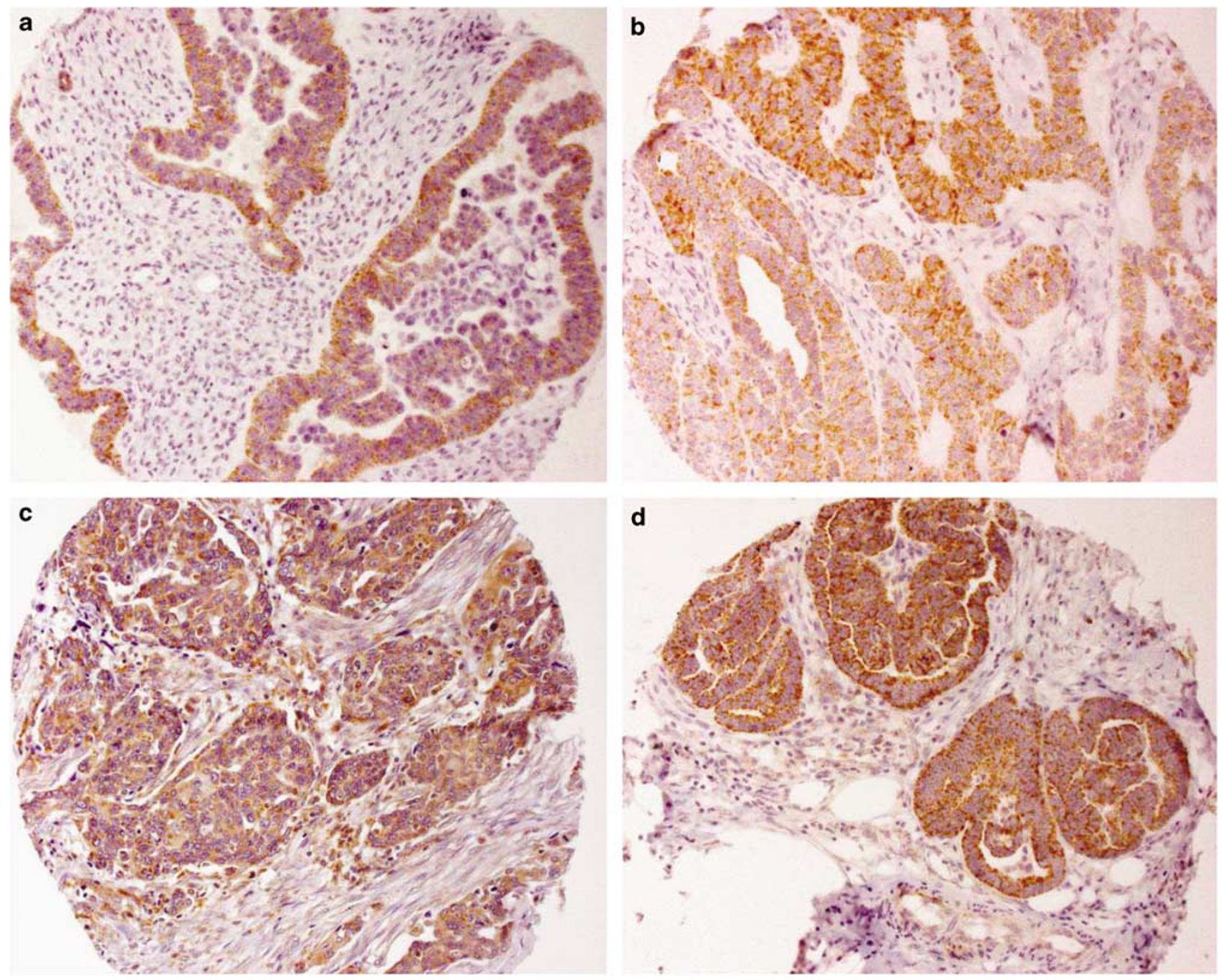

Figure 2 Marker expression by immunohistochemistry: (a) MMP1; (b) CD36; (c) HSP10; (d) FOSB; (e) GST; (f) pan-cathepsin; (g) p53; (h) Ki-67.

overexpression by immunohistochemistry was associated with a poor prognosis in both $\operatorname{colon}^{38}$ and esophageal ${ }^{39}$ cancers. However, no such prognostic study has been reported in ovarian cancer. MMP1 expression was found to be negligible in benign cystadenomas but it was overexpressed in both tumor and stromal cells of serous papillary carcinomas. ${ }^{40}$ Interestingly, a $2 \mathrm{G}$ mutation on the MMP1 promoter was found to be associated with MMP1 overexpression. ${ }^{41}$ The authors suggest that such genetic abnormality may be associated with an increased risk of developing ovarian cancer, although others did not reach such a conclusion. ${ }^{42}$

The fact that, of the 12 genes selected by microarrays comparing chemosensitive and chemoresistant tumors, HSP10 was the only significant marker of progression-free survival by immunohistochemistry is intriguing. This may suggest that the 2 -fold ratio between high and low expression by microarrays defined in our previous study, ${ }^{12}$ is not high enough to be clinically relevant by immunohistochemistry. Furthermore, we found no linear

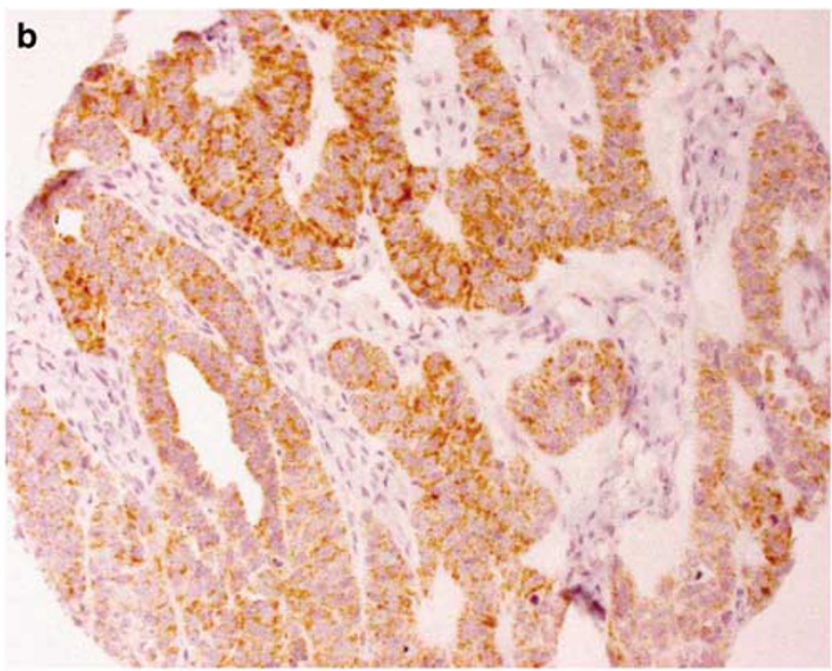


1008
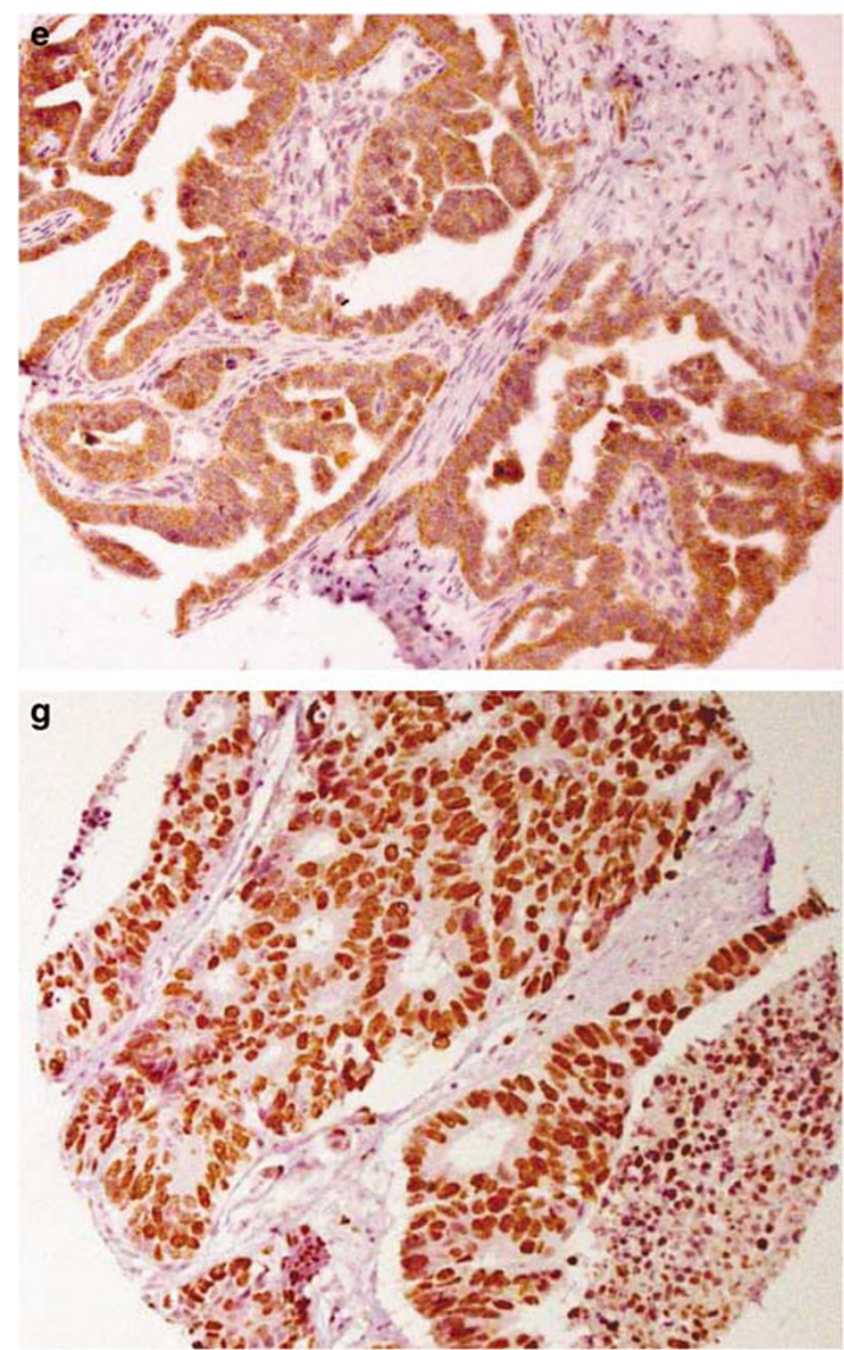
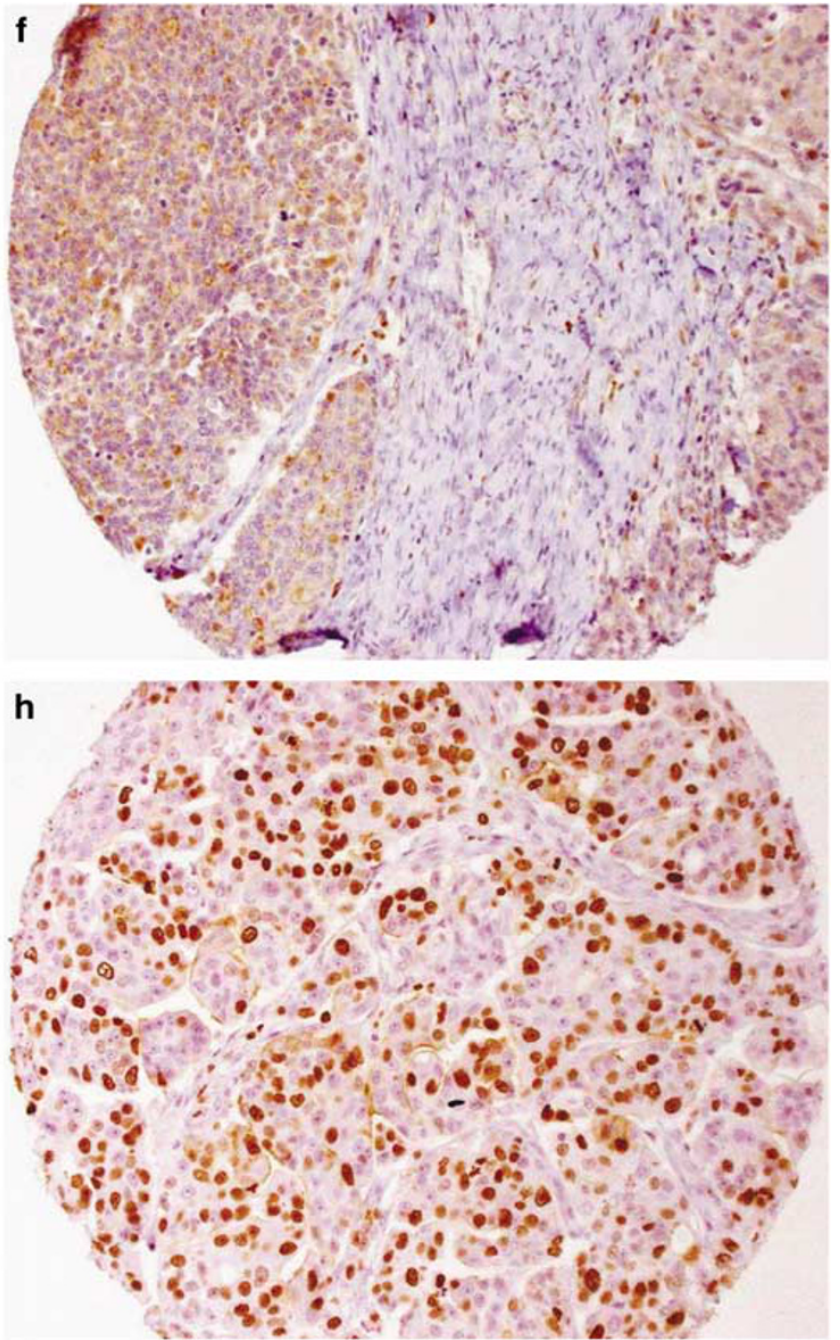

Figure 2 Continued.

Table 4 Cox regression analysis to predict progression-free survival

\begin{tabular}{|c|c|c|c|c|c|c|c|c|c|}
\hline \multirow[t]{2}{*}{ Marker } & \multirow[t]{2}{*}{ Value } & \multirow{2}{*}{$\begin{array}{l}\text { Frequency } \\
\qquad N(\%)\end{array}$} & \multirow{2}{*}{$\begin{array}{l}\text { Event } \\
n(\%)\end{array}$} & \multicolumn{3}{|c|}{ Crude } & \multicolumn{3}{|c|}{ Adjusted } \\
\hline & & & & $\mathrm{HR}$ & $95 \%$ CI & $P$-value & $\mathrm{HR}^{\mathrm{a}}$ & $95 \%$ CI & $P$-value \\
\hline \multirow[t]{2}{*}{ CD6 } & Negative & $128(81.0)$ & $103(80.5)$ & 1.0 & & & 1.0 & & \\
\hline & Positive & $30(19.0)$ & $27(90.0)$ & 1.13 & {$[0.74 ; 1.73]$} & 0.56 & 1.055 & {$[0.67 ; 1.65]$} & 0.81 \\
\hline \multirow[t]{2}{*}{ HSP10 } & Negative & $90(57.0)$ & $80(88.9)$ & 1.0 & & & 1.0 & & \\
\hline & Positive & $68(43.0)$ & $50(73.5)$ & 0.64 & {$[0.45 ; 0.91]$} & 0.01 & 0.60 & {$[0.42 ; 0.87]$} & 0.007 \\
\hline \multirow[t]{2}{*}{ FOSB } & Negative & $127(80.4)$ & $102(80.3)$ & 1.0 & & & 1.0 & & \\
\hline & Positive & 31 (19.6) & $28(90.3)$ & 1.15 & {$[0.76 ; 1.76]$} & 0.50 & 1.07 & {$[0.69 ; 1.66]$} & 0.77 \\
\hline \multirow[t]{2}{*}{ MMP1 } & Negative & 139 (88.0) & 113 (81.3) & 1.0 & & & 1.0 & & \\
\hline & Positive & 19 (12.0) & 17 (89.5) & 1.48 & {$[0.89 ; 2.47]$} & 0.13 & 1.61 & {$[0.94 ; 2.79]$} & 0.08 \\
\hline \multirow[t]{2}{*}{ GST } & Negative & 116 (73.4) & $92(79.3)$ & 1.0 & & & 1.0 & & \\
\hline & Positive & $42(26.6)$ & $38(90.5)$ & 1.25 & {$[0.86 ; 1.83]$} & 0.25 & 1.08 & {$[0.72 ; 1.61]$} & 0.70 \\
\hline \multirow[t]{2}{*}{ Pan-cathepsin } & Negative & $109(69.0)$ & $88(80.7)$ & 1.0 & & & 1.0 & & \\
\hline & Positive & $49(31.0)$ & $42(85.7)$ & 0.98 & {$[0.68 ; 1.42]$} & 0.92 & 0.92 & {$[0.61 ; 1.37]$} & 0.67 \\
\hline \multirow[t]{2}{*}{ p53 } & Negative & $67(42.4)$ & 55 (82.1) & 1.0 & & & 1.0 & & \\
\hline & Positive & $91(57.6)$ & $75(82.4)$ & 0.815 & {$[0.58 ; 1.15]$} & 0.24 & 0.83 & {$[0.58 ; 1.18]$} & 0.29 \\
\hline \multirow[t]{2}{*}{ Ki67 } & $<20 \%$ & $83(52.5)$ & 71 (85.5) & 1.0 & & & 1.0 & & \\
\hline & $>20 \%$ & $75(47.5)$ & $59(78.7)$ & 0.76 & {$[0.54 ; 1.08]$} & 0.13 & 0.72 & {$[0.51 ; 1.03]$} & 0.07 \\
\hline
\end{tabular}

${ }^{\mathrm{a}}$ Note: adjusted for age, stage, grade, baseline CA125 and type of chemotherapy. 


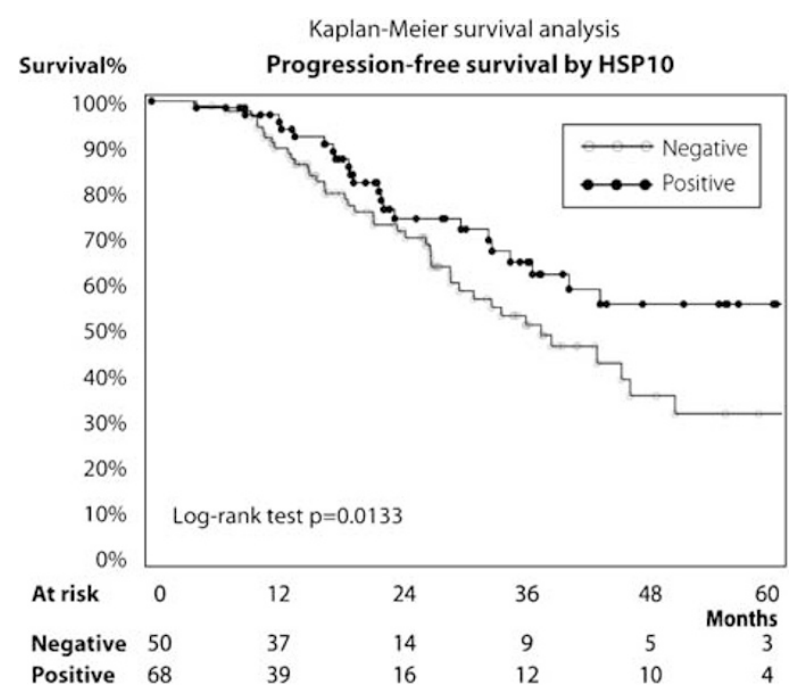

Figure 3 Kaplan-Meier curve for progression-free survival and HSP10.

correlation between gene expression obtained by microarray and protein expression obtained by immunohistochemistry. Current literature also shows that the correlation between mRNA and protein levels is insufficient to predict protein expression levels from quantitative mRNA data. Indeed, for some genes, while mRNA levels are of the same value, the protein levels may vary by more than 20-fold and, conversely, proteins with similar levels may have respective mRNA transcript levels that vary by as much as 30 -fold. ${ }^{43}$ Further studies should focus on the clinical and immunohistochemistry relevance of data obtained by microarrays.

We conclude that, despite a lack of direct relation between mRNA and proteins levels, gene expression analysis coupled with immunohistochemistry allowed us to identify high HSP10 and possibly, high proliferation and low MMP1 as potential markers of response to chemotherapy. Future studies should be aimed at developing a prognostic index combining the immunohistochemistry markers to predict the response to chemotherapy.

\section{Acknowledgements}

This study was financially supported by a grant from the Cancer Research Society of Canada (The Strategic Research Program on Genomics and Proteomics of Metastatic Cancer) and by the Cancer Research Network of the 'Fonds de la Recherche en Santé du Québec', Québec, Canada.

\section{Disclosure/Conflict of Interest}

There are no financial conflicts of interest with any organization and for any author of this article.

\section{References}

1 Holschneider CH, Berek J. Ovarian cancer: epidemiology, biology, and prognostic factors. Semin Surg Oncol 2000;19:3-10.

2 Ozols RF. Future directions in the treatment of ovarian cancer. Semin Oncol 2002;29:32-42.

3 Petit T, Velten M, d'Hombres A, et al. Long-term survival of 106 stage III ovarian cancer patients with minimal residual disease after second-look laparotomy and consolidation radiotherapy. Gynecol Oncol 2007;104:104-108.

4 Cannistra SA. Cancer of the ovary. N Engl J Med 2004;351:2519-2529.

5 Germain I, Tetu B, Brisson J, et al. Markers of chemoresistance in ovarian carcinomas: an immunohistochemical study of 86 cases. Int J Gynecol Pathol 1996;15:54-62.

6 Cherian MG, Jayasurya A, Bay BH. Metallothioneins in human tumors and potential roles in carcinogenesis. Mutat Res 2003;533:201-209.

7 Goff BA, Paley PJ, Greer BE, et al. Evaluation of chemoresistance markers in women with epithelial ovarian carcinoma. Gynecol Oncol 2001;81:18-24.

8 Schwartz DR, Kardia SL, Shedden KA, et al. Gene expression in ovarian cancer reflects both morphology and biological behavior, distinguishing clear cell from other poor-prognosis ovarian carcinomas. Cancer Res 2002;62:4722-4729.

9 Whiteside MA, Chen DT, Desmond RA, et al. A novel time-course cDNA microarray analysis method identifies genes associated with the development of cisplatin resistance. Oncogene 2004;23:744-752.

10 Helleman J, Jansen MP, Span PN, et al. Molecular profiling of platinum resistant ovarian cancer. Int J Cancer 2006;118:1963-1971.

11 Hartmann LC, Lu KH, Linette GP, et al. Gene expression profiles predict early relapse in ovarian cancer after platinum-paclitaxel chemotherapy. Clin Cancer Res 2005;11:2149-2155.

12 Bachvarov D, L'esperance S, Popa I, et al. Gene expression patterns of chemoresistant and chemosensitive serous epithelial ovarian tumors with possible predictive value in response to initial chemotherapy. Int J Oncol 2006;29:919-933.

13 L’Esperance S, Popa I, Bachvarova M, et al. Gene expression profiling of paired ovarian tumors obtained prior to and following adjuvant chemotherapy: molecular signatures of chemoresistant tumors. Int J Oncol 2006;29:5-24.

14 Silverberg SG. Histopathologic grading of ovarian carcinoma: a review and proposal. Int J Gynecol Pathol 2000;19:7-15.

15 Therasse P, Arbuck SG, Eisenhauer EA, et al. New guidelines to evaluate the response to treatment in solid tumors. European Organization for Research and Treatment of Cancer, National Cancer Institute of the United States, National Cancer Institute of Canada. J Natl Cancer Inst 2000;92:205-216.

16 Couture C, Raybaud-Diogene H, Tetu B, et al. p53 and Ki-67 as markers of radioresistance in head and neck carcinoma. Cancer 2002;94:713-722.

17 Calderwood SK, Khaleque MA, Sawyer DB, et al. Heat shock proteins in cancer: chaperones of tumorigenesis. Trends Biochem Sci 2006;31:164-172.

18 Pierpaoli EV. The role of Hsp70 in age-related diseases and the prevention of cancer. Ann NY Acad Sci 2005;1057:206-219. 
19 Cappello F. HSP60 and HSP10 as diagnostic and prognostic tools in the management of exocervical carcinoma. Gynecol Oncol 2003;91:661.

20 Maxwell PJ, Longley DB, Latif T, et al. Identification of 5-fluorouracil-inducible target genes using cDNA microarray profiling. Cancer Res 2003;63:4602-4606.

21 Cappello F, Rappa F, David S, et al. Immunohistochemical evaluation of PCNA, p53, HSP60, HSP10 and MUC-2 presence and expression in prostate carcinogenesis. Anticancer Res 2003;23:1325-1331.

22 Cappello F, Bellafiore M, David S, et al. Ten kilodalton heat shock protein (HSP10) is overexpressed during carcinogenesis of large bowel and uterine exocervix. Cancer Lett 2003;196:35-41.

23 Cappello F, David S, Rappa F, et al. The expression of HSP60 and HSP10 in large bowel carcinomas with lymph node metastase. BMC Cancer 2005;5:139-139.

24 Akyol S, Gercel-Taylor C, Reynolds LC, et al. HSP-10 in ovarian cancer: expression and suppression of T-cell signaling. Gynecol Oncol 2006;101:481-486.

25 Gandour-Edwards R, Trock BJ, Gumerlock P, et al. Heat shock protein and p53 expression in head and neck squamous cell carcinoma. Otolaryngol Head Neck Surg 1998;118:610-615.

26 Tetu B, Brisson J, Landry J, et al. Prognostic significance of heat-shock protein-27 in node-positive breast carcinoma: an immunohistochemical study. Breast Cancer Res Treat 1995;36:93-97.

27 Fortin A, Raybaud-Diogene H, Tetu B, et al. Markers of neck failure in oral cavity and oropharyngeal carcinomas treated with radiotherapy. Head Neck 2001;23: 87-93.

28 Kimura E, Enns RE, Alcaraz JE, et al. Correlation of the survival of ovarian cancer patients with mRNA expression of the $60-\mathrm{kD}$ heat-shock protein HSP-60. J Clin Oncol 1993;11:891-898.

29 Heslin MJ, Cordon-Cardo C, Lewis JJ, et al. Ki-67 detected by MIB-1 predicts distant metastasis and tumor mortality in primary, high grade extremity soft tissue sarcoma. Cancer 1998;83:490-497.

30 Grabenbauer GG, Muhlfriedel C, Rodel F, et al. Squamous cell carcinoma of the oropharynx: Ki-67 and p53 can identify patients at high risk for local recurrence after surgery and postoperative radiotherapy. Int J Radiat Oncol Biol Phys 2000;48: 1041-1050.

$31 \mathrm{Wu}$ TT, Chen JH, Lee YH, et al. The role of bcl-2, p53, and ki-67 index in predicting tumor recurrence for low-grade superficial transitional cell bladder carcinoma. J Urol 2000;163:758-760.
32 Petit T, Wilt M, Velten M, et al. Comparative value of tumour grade, hormonal receptors, Ki-67, HER-2 and topoisomerase II alpha status as predictive markers in breast cancer patients treated with neoadjuvant anthracycline-based chemotherapy. Eur J Cancer 2004;40: 205-211.

33 Raybaud-Diogene H, Fortin A, Morency R, et al. Markers of radioresistance in squamous cell carcinomas of the head and neck: a clinicopathologic and immunohistochemical study. J Clin Oncol 1997;15: 1030-1038.

34 Munstedt K, von Georgi R, Franke FE. Correlation between MIB1-determined tumor growth fraction and incidence of tumor recurrence in early ovarian carcinomas. Cancer Invest 2004;22:185-194.

35 Layfield LJ, Saria EA, Berchuck A, et al. Prognostic value of MIB-1 in advanced ovarian carcinoma as determined using automated immunohistochemistry and quantitative image analysis. J Surg Oncol 1997;66: 230-236.

36 Mita S, Nakai A, Maeda S, et al. Prognostic significance of Ki-67 antigen immunostaining (MIB-1 monoclonal antibody) in ovarian cancer. J Nippon Med Sch 2004;71:384-391.

37 Itamochi $\mathrm{H}$, Kigawa J, Sugiyama $\mathrm{T}$, et al. Low proliferation activity may be associated with chemoresistance in clear cell carcinoma of the ovary. Obstet Gynecol 2002;100:281-287.

38 Murray GI, Duncan ME, O'Neil P, et al. Matrix metalloproteinase-1 is associated with poor prognosis in colorectal cancer. Nat Med 1996;2:461-462.

39 Murray GI, Duncan ME, O'Neil P, et al. Matrix metalloproteinase-1 is associated with poor prognosis in oesophageal cancer. J Pathol 1998;185:256-261.

40 Behrens P, Rothe M, Florin A, et al. Invasive properties of serous human epithelial ovarian tumors are related to Ets-1, MMP-1 and MMP-9 expression. Int J Mol Med 2001;8:149-154.

41 Kanamori Y, Matsushima M, Minaguchi T, et al. Correlation between expression of the matrix metalloproteinase-1 gene in ovarian cancers and an insertion/ deletion polymorphism in its promoter region. Cancer Res 1999;59:4225-4227.

42 Wenham RM, Calingaert B, Ali S, et al. Matrix metalloproteinase-1 gene promoter polymorphism and risk of ovarian cancer. J Soc Gynecol Investig 2003; 10:381-387.

43 Gygi SP, Rochon Y, Franza BR, et al. Correlation between protein and mRNA abundance in yeast. Mol Cell Biol 1999;19:1720-1730. 